\title{
CORRECTION TO: EFFECTS OF Y AND ADDITION OF REFINERS ON HOT TEARING SUSCEPTIBILITY OF MgZn-BASED ALLOY
}

\section{Z. Q. Wei, S. M. Liu, Z. Liu and Y. Wang}

Shenyang University of Technology, Shenyang 110870, People's Republic of China

Key Laboratory of Magnesium Alloys and the Processing Technology of Liaoning Province, Shenyang 110870, People's Republic of China

\section{Z. J. Zhou}

Institute of Metal Research, Chinese Academy of Sciences, Shenyang 110016, People's Republic of China Key Laboratory of Magnesium Alloys and the Processing Technology of Liaoning Province, Shenyang 110870, People's Republic of China

\section{Correction to:}

International Journal of Metalcasting https://doi.org/10.1007/s40962-021-00591-x

The authors' affiliations are correct as reflected here. The original article has been corrected.
Publisher's Note Springer Nature remains neutral with regard to jurisdictional claims in published maps and institutional affiliations.

The original article can be found online at https://doi.org/10.1007/ s40962-021-00591-x. 